\title{
Breast Cancer Epidemiology
}

National Cancer Institute

\section{Source}

National Cancer Institute. Breast Cancer Epidemiology. NCI Thesaurus. Code C18665.

Environmental or molecular epidemiology of human breast cancer. 